\title{
Alkhurma Hemorrhagic Fever Virus RNA in Hyalomma rufipes Ticks Infesting Migratory Birds, Europe and Asia Minor
}

\section{Tove Hoffman, Mats Lindeborg, Christos Barboutis, Kiraz Erciyas-Yavuz, Magnus Evander, Thord Fransson, Jordi Figuerola, Thomas G.T. Jaenson, Yosef Kiat, Per-Eric Lindgren, Åke Lundkvist, Nahla Mohamed, Sara Moutailler, Fredrik Nyström, Björn Olsen, Erik Salaneck}

Alkhurma hemorrhagic fever virus RNA was detected in immature Hyalomma rufipes ticks infesting northward migratory birds caught in the North Mediterranean Basin. This finding suggests a role for birds in the ecology of the Alkhurma hemorrhagic fever virus and a potential mechanism for dissemination to novel regions. Increased surveillance is warranted.

\footnotetext{
A lkhurma hemorrhagic fever virus (AHFV) was identified in 1995 after an outbreak of viral hemorrhagic fever in Jeddah Province, Saudi Arabia (1). This virus is a variant of Kyasanur Forest disease virus (KFDV), which is endemic in eastern India, and a member of the mammalian tickborne flaviviruses (2). An association between Alkhurma hemorrhagic fever cases and livestock handling was identified early on, suggesting goats and sheep are potential reservoirs (3). Furthermore, AHFV has been identified in Ornithodoros savignyi soft ticks and Hyalomma dromedarii hard ticks (potential vectors) in Saudi Arabia, both of which are associated with camels (potential reservoir) $(4,5)$. Alkhurma hemorrhagic fever is endemic in several provinces of Saudi Arabia; sporadic cases have been reported in Africa near

Author affiliations: Uppsala University, Uppsala, Sweden

(T. Hoffman, M. Lindeborg, T.G.T. Jaenson, A.. Lundkvist,

B. Olsen, E. Salaneck); Hellenic Ornithological Society/Birdlife, Athens, Greece (C. Barboutis); Ondokuz Mayis University, Samsun, Turkey (K. Erciyas-Yavuz); Umeå University, Umeå, Sweden (M. Evander, N. Mohamed); Swedish Museum of Natural History, Stockholm, Sweden (T. Fransson); Estación Biológica de Doñana, Sevilla, Spain (J. Figuerola); Ciber Epidemilogía y Salud Pública, Madrid, Spain (J. Figuerola); Hebrew University of Jerusalem, Jerusalem, Israel (Y. Kiat); Linköping University, Linköping, Sweden (P.-E. Lindgren, F. Nyström); Agence Nationale de Sécurité Sanitaire de l'Alimentation, Maisons-Alfort, France (S. Moutailler)
}

DOI: https://doi.org/10.3201/eid2405.171369 the Egypt-Sudan border and cases of seropositivity in Djibouti (6-8) (Figure 1). AHFV RNA has also been detected in Amblyomma lepidum ticks collected from cattle in Djibouti (9).

The clinical manifestation of Alkhurma hemorrhagic fever resembles that of other viral hemorrhagic fevers: initial malaise and influenza-like symptoms, followed by encephalitis, icterus, and ecchymosis. Case fatality is $\approx 25 \%$ but could be considerably lower, considering mild cases are probably undiagnosed (1). It has been suggested that both KFDV and AHFV originated in Africa and that, subsequently, KFDV spread to India and AHFV to Saudi Arabia, KFDV possibly disseminating farther to southern China by migratory birds (2). Also, other pathogens have been found to disseminate by means of ticks on migratory birds (10). In light of these findings, case reports in Africa (6-8), and increasing case frequency in Saudi Arabia (11), we investigated whether ticks infesting migratory birds en route from Africa to Europe and Asia during springtime carry AHFV.

\section{The Study}

We collected ticks from birds migrating northward initially at 2 bird observatories on the Mediterranean islands Capri (Italy; $40^{\circ} 33^{\prime} \mathrm{N}, 14^{\circ} 15^{\prime} \mathrm{E}$ ) and Andikíthira (Greece; $35^{\circ} 51^{\prime} \mathrm{N}, 23^{\circ} 18^{\prime} \mathrm{E}$ ) during spring of 2009 and 2010. We captured 14,824 birds ( 78 species) during their yearly migration, presumably leaving Africa for breeding grounds in Europe or Asia. We collected 747 ticks, 88\% of which were identified morphologically as members of the complex $H$. marginatum sensu lato (s.1.), most likely $H$. rufipes and $H$. marginatum. We screened cDNA for AHFV by real-time PCR with primers targeting the $5^{\prime}$ untranslated region of AHFV (12). Five fully engorged ticks, morphologically and molecularly determined to be H. marginatum s.l., likely H. rufipes (GenBank accession nos. MH061004-MH061008, MH061010-MH061014), tested positive for AHFV RNA in 2 separate analyses. These 5 ticks ( 4 nymphs, 1 larva) were collected at Andikíthira in 2010 (Table) from 3 bird species that winter in sub-Saharan Africa and breed in Europe (Figure 1, panels A-C). One sedge warbler (Acrocephalus schoenobaenus) carried 2 AHFV-positive nymphs. Sequencing of the $5^{\prime}$ untranslated region amplicons revealed 2 identical 
Table. Characteristics of birds infested by ticks testing positive for Alkhurma hemorrhagic fever virus RNA by real-time PCR, Greece and Turkey, 2010 and 2014

\begin{tabular}{|c|c|c|c|c|c|}
\hline Ring no. & Bird species & $\begin{array}{l}\text { Capture } \\
\text { date }\end{array}$ & Tick species & Life stage & $\begin{array}{l}\text { Capture } \\
\text { site }\end{array}$ \\
\hline B913855 & Eastern woodchat shrike (Lanius senator niloticus) & 2010 May 5 & $\begin{array}{c}\text { Hyalomma marginatum sensu } \\
\text { lato }(H \text {. rufipes })\end{array}$ & Nymph & Greece \\
\hline A228919 & Sedge warbler (Acrocephalus schoenobaenus) & 2010 May 7 & H. marginatum s.I. (H. rufipes) & Nymph & Greece \\
\hline A225683 & Western yellow wagtail (Motacilla flava) & 2010 May 9 & H. marginatum s.I. (H. rufipes) & Larva & Greece \\
\hline A225166 & Sedge warbler (A. schoenobaenus) & 2010 May 13 & H. marginatum s.I. (H. rufipes) & Nymph & Greece \\
\hline A225166 & Sedge warbler ( $A$. schoenobaenus) & 2010 May 13 & H. marginatum s.I. (H. rufipes) & Nymph & Greece \\
\hline JB53791 & Common redstart (Phoenicurus phoenicurus) & 2014 Apr 29 & H. marginatum s.I. (H. rufipes) & Adult & Turkey \\
\hline
\end{tabular}

72-bp sequences. BLAST (http://www.ncbi.nlm.nih.gov/ blast/) and comparative analyses revealed high identity to AHFV and KFDV reference sequences, despite a region with 7 consecutive mismatching nucleotides and a 14-nt deletion (Figure 2, panel A). Apart from this difference, $100 \%$ identity was seen with all other AHFV and KFDV sequences available in GenBank.

Because of these results, we included additional bird observatories and collection sites along with Capri and Andikithira in spring of 2014 and 2015: the Anapodaris River, Crete, Greece $\left(34^{\circ} 59^{\prime} \mathrm{N}, 25^{\circ} 17^{\prime} \mathrm{E}\right)$; Huelva Province, Spain $\left(37^{\circ} 30^{\prime} \mathrm{N}, 5^{\circ} 30^{\prime} \mathrm{W}\right)$; Sevilla Province, Spain $\left(37^{\circ} 33^{\prime} \mathrm{N}\right.$, $\left.6^{\circ} 55^{\prime} \mathrm{W}\right)$; Canary Islands, Spain $\left(28^{\circ} 9^{\prime} \mathrm{N}, 15^{\circ} 25^{\prime} \mathrm{W}\right)$; Jerusalem, Israel $\left(31^{\circ} 47^{\prime} \mathrm{N}, 35^{\circ} 13^{\prime} \mathrm{E}\right)$; and the Kizilirmak Delta, Turkey $\left(41^{\circ} 38^{\prime} \mathrm{N}, 36^{\circ} 05^{\prime} \mathrm{E}\right)$. We ringed 22,069 birds $(137$ species) and collected 1,024 ticks. RNA was extracted at
Uppsala University (Uppsala, Sweden) and sent to Agence Nationale de Sécurité Sanitaire de l'Alimentation (Paris, France) for high-throughput screening by microfluidic realtime PCR (Biomark Dynamic Arrays, Fluidigm, South San Francisco, CA, USA) targeting multiple tickborne viruses (S. Moutailler, unpub. data). One fully engorged adult tick, molecularly determined to be H. marginatum s.l. (GenBank accession nos. MH061009, MH061015), likely H. rufipes, collected from a common redstart (Phoenicurus phoenicurus) in Turkey tested positive for AHFV RNA (Table) when using a set of primers and probe that amplifies part of the KFDV/AHFV premembrane region (Kyasanur_poly_F, 5'-ACACGATGCACACACCTGC-3'; Kyasanur_poly_R, 5'- CACCAATGAAACTCTAGTCGTC-3'; Kyasanur poly_P, 5'-AGAACCGGGACTTTGTCTCAGGGAC-3'). To confirm this finding, a subsequent real-time PCR was

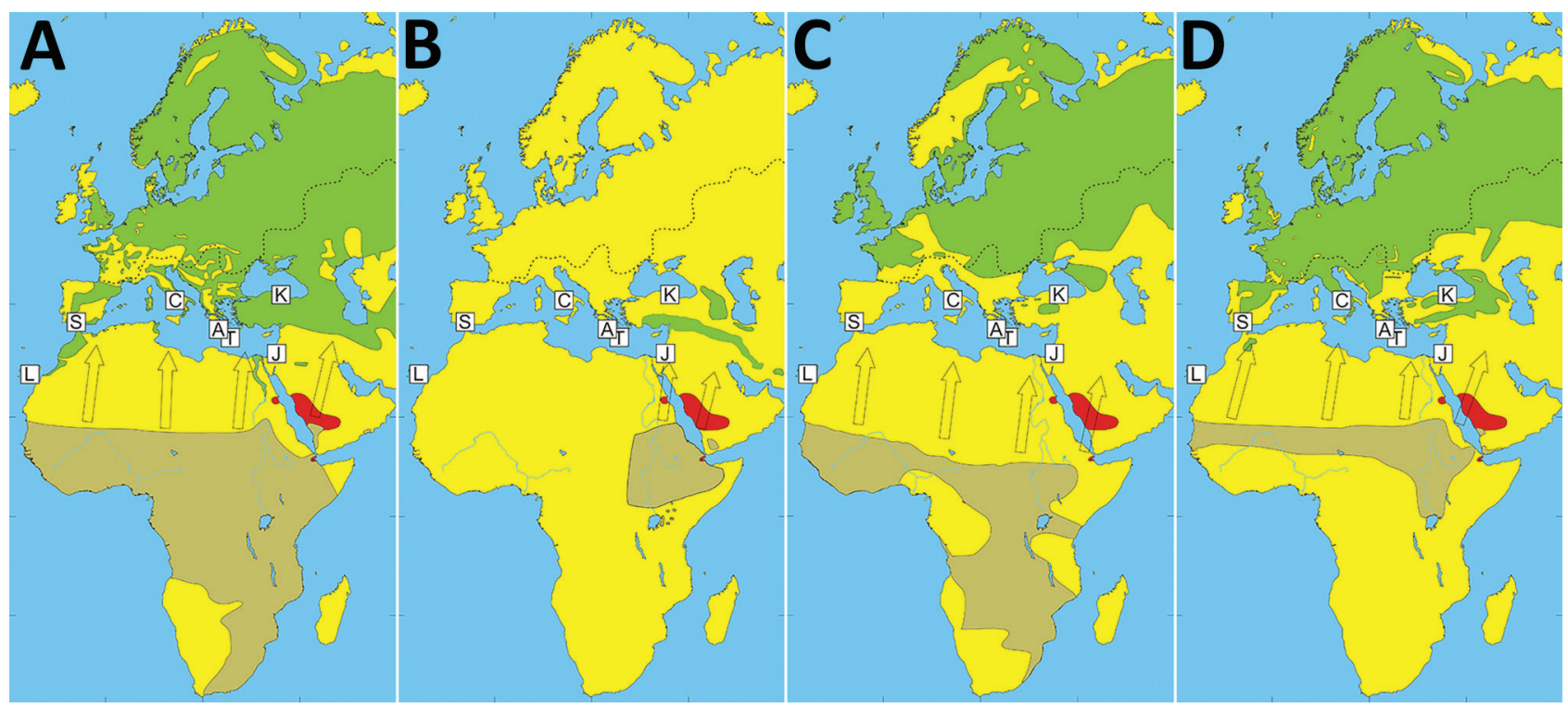

Figure 1. Wintering (light brown) and breeding (green) locations and springtime migratory routes (arrows) of birds testing positive for Alkhurma hemorrhagic fever virus (AHFV) RNA in Greece and Turkey, 2010 and 2014. The 4 bird species found infested by Hyalomma ticks carrying AHFV RNA were the western yellow wagtail (Motacilla flava) (A), eastern woodchat shrike (Lanius senator niloticus) (B), sedge warbler (Acrocephalus schoenobaenus) (C), and common redstart (Phoenicurus phoenicurus) (D). Red shading indicates areas where AHFV has been detected. The dashed line shows the approximate northern geographic boundary of $H$. marginatum complex ticks (based on information from the European Center for Disease Prevention and Control, https://ecdc.europa.eu/en/disease-vectors/ surveillance-and-disease-data/tick-maps). H. rufipes ticks have a wide geographic distribution in Africa and are present in Saudi Arabia. Collection sites are labeled: Andikíthira, Greece (A); Capri, Italy (C); Jerusalem, Israel (J); Kizilirmak Delta, Turkey (K); Huelva and Sevilla Provinces, Spain (S); Canary Islands, Spain (L); and Crete, Greece (T). Maps created based on information from The Birds of the Western Palearctic, volumes 5-7, Oxford (UK): Oxford University Press; 1988, 1992, 1993. 


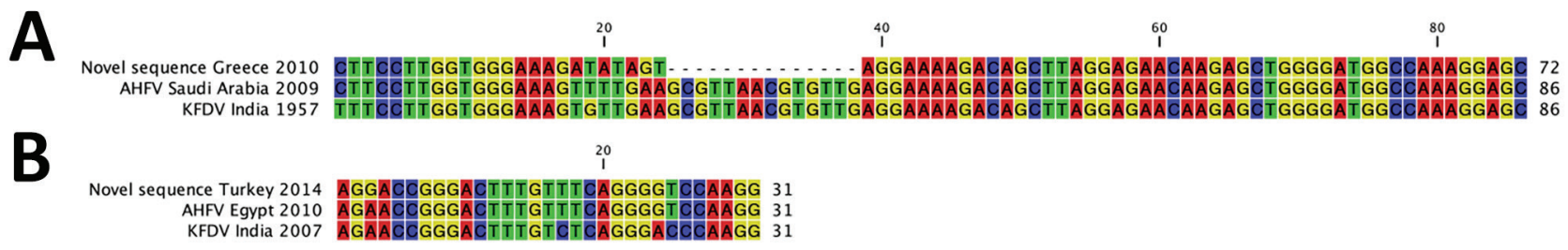

Figure 2. Nucleotide alignments of novel AHFV sequences obtained from Hyalomma marginatum sensu lato ticks (likely $H$. rufipes) with reference AHFV and KFDV sequences. A) Partial alignment of $5^{\prime}$ untranslated region of AHFV obtained from tick collected from bird on Andikithira, Greece, 2010, with corresponding reference sequences of AHFV (GenBank accession no. JF416957) and KFDV (GenBank accession no. HM055369). B) Partial alignment of premembrane sequence of AHFV obtained from tick collected from bird in Turkey, 2014, with corresponding reference sequences of AHFV (GenBank accession no. JX914663) and KFDV (GenBank accession no. JQ434075). AHFV, Alkhurma hemorrhagic fever virus; KFDV, Kyasanur Forest disease virus.

performed with the same primers and probe. Alignment of the 31-bp fragment revealed a single nucleotide change compared with available AHFV sequences and 3 or 4 differences compared with available KFDV sequences (Figure 2, panel B). The methods used did not enable virus isolation and propagation; therefore, acquisition of further sequence information proved difficult. The common redstart also breeds in Europe and winters in sub-Saharan Africa, similarly to the 3 previously mentioned bird species (Figure 1, panel D).

\section{Conclusions}

We detected AHFV/KFDV RNA in 6 of 1,771 investigated ticks. Although we could not differentiate between KFDV and AHFV on the basis of the short sequences analyzed, we suggest these sequences represent AHFV because this supposition is geographically and ecologically more plausible. Our findings are insufficient to establish the role of the $H$. rufipes tick as an AHFV vector. However, detection of AHFV RNA in Europe and Asia Minor raises concerns for conceivable dissemination of the virus to these areas, facilitated by climate change resulting in increased distribution of Hyalomma spp. ticks.

H. rufipes ticks are widely distributed in Africa and are also present on the Arabian Peninsula, along the Red Sea coast (13). The H. rufipes species is a 2-host tick; that is, the nymph remains attached to ingest blood on the same host it did for its first blood meal as a larva. Immature ticks usually infest birds or small mammals (e.g., hares), whereas adult ticks feed on larger mammals (e.g., camels, buffaloes, cattle, and large birds) (13). Consequently, the AHFV-positive ticks (except the 1 adult) most likely had fed only on the bird to which they were attached. This assumption implies that an immature tick could have acquired the virus vertically from its mother, from its putatively viremic avian host, or by cofeeding transmission, which can occur when ticks feed close to $\geq 1$ infective tick $(14,15)$. However, in this case, co-feeding transmission is less plausible because the 2 ticks attached to the same bird were not located close to each other (on the beak and nape). For several tickborne viruses, including KFDV, vertical transmission from the adult female tick to the eggs occurs. However, the prevalence of transovarial infection in nature is considered low (14). The 1 positive adult tick could have acquired virus in any of these ways or from a previous mammalian blood meal.

To our knowledge, birds have not been shown to play a role in the ecology or epidemiology of AHFV, and this tick species has not been identified previously as a possible vector. Our finding of this virus in ticks infesting birds en route from Africa to Europe and Asia, together with clinical cases in southern Egypt, the detection of AHFV RNA in ticks, and cases of seropositivity in Djibouti, could indicate a wider geographic distribution of the virus throughout eastern Africa and in novel regions. Further investigations of AHFV ecology and modes of transmission, including the potential role of Hyalomma ticks as vectors and passerine birds as reservoirs or distributors of potentially infected ticks, as well as increased surveillance, are needed.

\section{Acknowledgments}

We thank Dario Piacentini, Laura Gangoso, Rafael Gutierrez, Manuel Vazquez, Jose Luis Arroyo, Alberto Pastoriza, and all others involved in the tick collections and Peter Wilhelmsson for sample organization.

Ondokuz Mayis University (project no. PYO.

ORN.1901.15.001) financially supported the ringing activity at the Kizilirmak Delta. P.-E.L. was supported by the EU-Interreg program, ScandTick Innovation project, and J.F. was supported by RNM-7038 project from Junta de Andalucía. T.G.T.J.'s research is funded by the European Centre for Disease Prevention and Control and the European Food Safety Authority (via VectorNet), Carl Trygger's Stiftelse, Helge Axson Johnson's Stiftelse, Längmanska Kulturfonden, and Magnus Bergvall's Stiftelse. The Andikíthira Bird Observatory was supported by the A.G. Leventis Foundation. This is publication no. 23 from the Andikíthira Bird Observatory. 


\section{About the Author}

Ms. Hoffman is a doctoral student at the Zoonosis Science Center, Department of Medical Science, Uppsala University, Uppsala, Sweden. She has a background in infection biology and a special research interest in vectorborne infections, particularly the potential role of migratory birds in the transmission of tickborne pathogens.

\section{References}

1. Al-Tawfiq JA, Memish ZA. Alkhurma hemorrhagic fever virus. Microbes Infect. 2017;19:305-10. http://dx.doi.org/ 10.1016/j.micinf.2017.04.004

2. Dodd KA, Bird BH, Khristova ML, Albariño CG, Carroll SA, Comer JA, et al. Ancient ancestry of KFDV and AHFV revealed by complete genome analyses of viruses isolated from ticks and mammalian hosts. PLoS Negl Trop Dis. 2011;5:e1352. http://dx.doi.org/10.1371/ journal.pntd.0001352

3. Madani TA. Alkhumra virus infection, a new viral hemorrhagic fever in Saudi Arabia. J Infect. 2005;51:91-7. http://dx.doi.org/10.1016/j.jinf.2004.11.012

4. Charrel RN, Fagbo S, Moureau G, Alqahtani MH, Temmam S, de Lamballerie X. Alkhurma hemorrhagic fever virus in Ornithodoros savignyi ticks. Emerg Infect Dis. 2007;13:153-5. http://dx.doi.org/10.3201/ eid1301.061094

5. Mahdi M, Erickson BR, Comer JA, Nichol ST, Rollin PE, AlMazroa MA, et al. Kyasanur Forest disease virus Alkhurma subtype in ticks, Najran Province, Saudi Arabia. Emerg Infect Dis. 2011;17:945-7. http://dx.doi.org/ 10.3201/eid1705.101824

6. Carletti F, Castilletti C, Di Caro A, Capobianchi MR, Nisii C, Suter F, et al. Alkhurma hemorrhagic fever in travelers returning from Egypt, 2010. Emerg Infect Dis. 2010;16:1979-82. http://dx.doi.org/10.3201/ eid1612.101092

7. Andayi F, Charrel RN, Kieffer A, Richet H, Pastorino B, Leparc-Goffart I, et al. A sero-epidemiological study of arboviral fevers in Djibouti, Horn of Africa. PLoS Negl Trop
Dis. 2014;8:e3299. http://dx.doi.org/10.1371/

journal.pntd.0003299

8. Musso M, Galati V, Stella MC, Capone A. A case of Alkhumra virus infection. J Clin Virol. 2015;66:12-4. http://dx.doi.org/10.1016/j.jcv.2015.02.019

9. Horton KC, Fahmy NT, Watany N, Zayed A, Mohamed A, Ahmed AA, et al. Crimean Congo hemorrhagic fever virus and Alkhurma (Alkhumra) virus in ticks in Djibouti. Vector Borne Zoonotic Dis. 2016;16:680-2. http://dx.doi.org/ 10.1089/vbz.2016.1951

10. Rumer L, Graser E, Hillebrand T, Talaska T, Dautel H, Mediannikov O, et al. Rickettsia aeschlimannii in Hyalomma marginatum ticks, Germany. Emerg Infect Dis. 2011;17:325-6. http://dx.doi.org/10.3201/eid1702.100308

11. Madani TA, Azhar EI, Abuelzein TM, Kao M, Al-Bar HMS, Abu-Araki H, et al. Alkhumra (Alkhurma) virus outbreak in Najran, Saudi Arabia: epidemiological, clinical, and laboratory characteristics. J Infect. 2011;62:67-76. http://dx.doi.org/10.1016/j.jinf.2010.09.032

12. Madani TA, Kao M, Azhar EI, Abuelzein TM, Al-Bar HMS, Abu-Araki H, et al. Successful propagation of Alkhumra (misnamed as Alkhurma) virus in C6/36 mosquito cells. Trans R Soc Trop Med Hyg. 2012;106:180-5. http://dx.doi.org/10.1016/j.trstmh.2011.11.003

13. Apanaskevich D, Horak I. The genus Hyalomma Koch, 1844: v. re-evaluation of the taxonomic rank of taxa comprising the H. (Euhyalomma) marginatum koch complex of species (Acari: Ixodidae) with redescription of all parasitic stages and notes on biology. Int J Acarol. 2008;34:13-42. http://dx.doi.org/10.1080/01647950808683704

14. Sonenshine DE, Roe RM. Biology of ticks. 2nd ed. New York: Oxford University Press; 2013.

15. Labuda M, Jones LD, Williams T, Danielova V, Nuttall PA. Efficient transmission of tick-borne encephalitis virus between cofeeding ticks. J Med Entomol. 1993;30:295-9. http://dx.doi.org/10.1093/jmedent/30.1.295

Address for correspondence: Erik Salaneck, Uppsala University, Department of Medical Science, SE-751 85 Uppsala, Sweden; email: erik.salaneck@medsci.uu.se 